\title{
Medicare Auctions: \\ A Case Study of Market Design in Washington, DC
}

\author{
Peter Cramton \\ University of Maryland \\ pcramtonegmail.com
}

\begin{abstract}
One sensible way to reduce healthcare costs is to harness market forces, where practical, to nurture competition and innovation. Lower prices and improved services should follow. However, the switch to market pricing is not an easy one. Medicare's experience with medical supplies illustrates the challenges and offers some important lessons. The key lesson is that government programs can benefit from introducing market methods, but doing so requires good market design-something that may not come naturally to the implementing agency, especially in light of political forces and organizational inertia.

An auction design for Medicare Durable Medical Equipment is presented. The design addresses the flaws in the current program. Bids are binding commitments. Each bid binds the bidder to particular performance obligations depending on the auction outcome. The bids are made credible through a rigorous qualification one month before the auction. Each bidder provides a financial guarantee in the form of a bid bond or a deposit in proportion to the bidder's capacity. Capacity is objectively estimated based on the bidder's supply in recent years. Each winner provides a performance guarantee in proportion to the winner's estimated volume won. The auction establishes a market clearing price for each product in each service area. The price paid to all suppliers is the clearing price that balances supply and demand. These prices are found in a simultaneous descending clock auction, a simple price discovery process that allows both substitutions across items and complementarities. Competition in the auction comes from new entry or the expansion of existing suppliers into new product categories and service areas. After the auction, the winners compete for Medicare beneficiaries by offering quality products and services. Thus, beneficiary choice is used to further strengthen incentives to provide high quality products and services.
\end{abstract}

